\section{Seizure relapse following medication withdrawal in childhood epilepsy}

National Institute for Health and Clinical Excellence guidance states that the risks and benefits of continuing or withdrawing anti epileptic drug (AED) therapy should be discussed with individuals, and their families and/or carers where appropriate, who have been seizure free for at least 2 years'. We report the outcome of withdrawal of AED's in a group of children managed in a secondary care community based paediatric epilepsy service.

We studied 105 children from whom anti-epileptic medication had been withdrawn (56 males and 49 females). The age of first seizure ranged from 1 month to 16 years 9 months and the median age was 5 years 9 months.

Of the 105 children and young people, 34 $(32.4 \%)$ had a recurrence of their seizures after medication was stopped. This is a similar finding to that of Shinnar et al who suggested that $75 \%$ of children can come off their anti-epileptic medication without recurrence if they have been seizure free for 2 years on treatment.

When considering the time elapsed between medication withdrawal and seizure recurrence, $23.3 \%$ relapsed during weaning or within a month of medication discontinuation. Cumulative relapse rates were 53.3\% of children within 6 months, $66.7 \%$ during the first year and $90 \%$ within 3 years. Our findings agree with those of Matricardi et $a^{\beta}$ who found that $30 \%$ of those who will relapse will do so during weaning (up to 6 months), $75 \%$ will do so during the first year and $98 \%$ will do so within 3 years.

With respect to type of epilepsy, 30.2\% of those with generalised, $35.7 \%$ of those with focal and $40 \%$ of those with unclassified epilepsies relapsed respectively when withdrawn from the anti-epileptic medication. This supports the findings of Dooley et $a l^{4}$ who described generalised epilepsy as having an increased likelihood of achieving remission compared to other forms of epilepsy. Of the $32(39 \%)$ patients who were treated with anti-epileptic medication for less than 2 years, $43.8 \%$ experienced a recurrence of seizures following drug withdrawal. In comparison, $46 \%$ of patients treated for longer than 2 years experienced seizure recurrence.

It is useful to have ball-park figures to give families some idea of the risks and possible time scales of recurrence of seizures when withdrawing AEDs. These figures come from bundling together outcomes from groups of children with different epilepsies-more specific and worthwhile advice would come from taking account of the cause and the epilepsy syndrome if possible.

\section{Daniel Hindley, ${ }^{1}$ Harriet Staniforth ${ }^{2}$}

'Halliwell Children's Centre, Aylesford Walk, Halliwell, Bolton, UK

${ }^{2}$ NHS, Eckington, Sheffield, UK

Correspondence to Dr Harriet Staniforth, Doncaster Royal Infirmary, South Yorkshire;

harrietstaniforth@doctors.org.uk

Competing interests None.

Provenance and peer review Not commissioned; externally peer reviewed.

Accepted 24 August 2010

Published Online First 7 October 2010

Arch Dis Child 2011;96:113.

doi:10.1136/adc.2010.199455

\section{REFERENCES}

1. National Collaborating Centre for Primary Care. The Diagnosis and Management of the Epilepsies in Adults and Children in Primary and Secondary Care. London, UK: Royal College of General Practitioners 2004:525.

2. Shinnar S, Vining EP, Mellits ED, et al. Discontinuing antiepileptic medication in children with epilepsy after two years without seizures. A prospective study. N Engl J Med 1985;313:976-80.

3. Matricardi A, Bertamino F, Risso D. Discontinuation of anti-epileptic therapy: a retrospective study of 86 children and adolescents. Ital J Neurol Sci 1995;16:613-22.

4. Dooley J, Gordon K, Camfield P, et al. Discontinuation of anticonvulsant therapy in children free of seizures for 1 year: a prospective study. Neurology 1996;46:969-74.
Table 1 Referral categories

\begin{tabular}{lrr}
\hline Category & No & \multicolumn{1}{l}{$\%$} \\
\hline Gastroenterology & 167 & 16.7 \\
Dermatology & 96 & 9.6 \\
Allergy & 91 & 9.1 \\
UTI & 84 & 8.4 \\
Neurology & 75 & 7.5 \\
Cardiology & 58 & 5.8 \\
Lumps and bumps & 52 & 5.2 \\
Orthopaedics /rheumatology & 51 & 5.1 \\
Surgery & 49 & 4.9 \\
Respiratory & 43 & 4.3 \\
Endocrinology & 38 & 3.8 \\
Headaches & 36 & 3.6 \\
Enuresis & 32 & 3.2 \\
Behaviour/Psych & 24 & 2.4 \\
New born exam concern & 20 & 2.0 \\
Developmental & 19 & 1.9 \\
Failure to thrive & 19 & 1.9 \\
Fatigue & 8 & 0.8 \\
Obesity & 2 & 0.2 \\
ENT & 1 & 0.1 \\
Others & 31 & 3.1 \\
\hline
\end{tabular}

